\title{
Urologic oncology during the COVID-19 pandemic
}

\author{
Manas Sharma $^{1}$, Rajendra B. Nerli ${ }^{*}$, Shridhar C. Ghagane ${ }^{2}$ \\ 'Department of Urology, JN Medical College, KLE Academy of Higher Education \& Research, JNMC Campus, \\ Belagavi-590010, Karnataka, India \\ 2Urinary Biomarkers Research Centre, Department of Urology, KLES Kidney Foundation, KLES Dr. Prabhakar Kore \\ Hospital \& Medical Research Centre, Nehru Nagar, Belagavi-590010, Karnataka, India
}

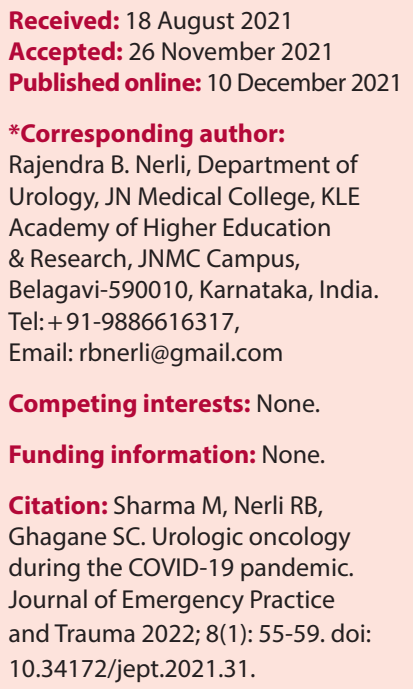

\begin{abstract}
The COVID-19 pandemic will have numerous consequences in the management of patients with genitourinary cancers. As we are struggling to best exploit our limited health-care resources in managing COVID-19 infected patients, we need to rethink our approach to provide the best medical care for cancer patients in the time of this global crisis. There is a need for a decision-making algorithm which takes into account the age, presenting symptoms, comorbid illnesses, access to health-care services, and availability of qualified health-care personnel. We must provide support, a clear and comprehensible information along with essential care to the patients seeking medical opinion during a time of this unforeseen global health crisis. In this mini review we have made an attempt to prioritize the necessity of intervention in urological oncology patients as per various national and international guidelines. This approach should be tailored as per locally available healthcare resources and the burden of COVID-19 infected cases in that region.

Keywords: Urology, Oncology, COVID-19, Pandemic
\end{abstract}

\section{Introduction}

The coronavirus pandemic will have numerous consequences in the management of patients with genitourinary cancers. As we are struggling to best utilize our limited health-care resources in catering to COVID-19 infected patients, we need to rethink our strategy to give the best medical care possible for cancer patients in the time of this global crisis. To contain the spread of viral illness, lockdowns have been implemented at the national, state, and district levels. This is proving to be beneficial as we can minimize the community spread of this pandemic. However, the restricted movement of the population is leading to difficulties in providing health-care consultation and follow-up for cancer patients. Not only the management of non-oncologic urological emergencies is a priority, but also the treatment of high-risk cancers is a prime concern. The malignancies carrying the most threat to survival in the short- and medium-term should be timely dealt on a priority basis.

In this mini-review, we aim to highlight that genitourinary cancer care requires a decision-making algorithm taking into account the age, pathology, comorbidities of the patients and the available health-care resources.
Renal Cancer

Early-stage and locally advanced renal cancer is a heterogeneous group of disease in which the following scenarios should be taken into consideration for management:

Cystic renal cell carcinoma (Bosniak Class III/IV) has a low metastatic potential; hence, amenable for monitoring (1). $\mathrm{T}_{1 \mathrm{a}}$ tumors, irrespective of their histology, are known to be slowly growing tumors with a low probability of metastasis. Studies have proven that such cases can be kept on surveillance (2). A few studies have reported that $\mathrm{T}_{1 \mathrm{~b}}-\mathrm{T}_{2}$ renal masses also have a slow rate of growth and infrequent accounts of metastasis. A multi-disciplinary team should take treatment decisions along with patients considering that this data is an extrapolation from retrospective series with a small patient cohort $(3,4)$. Tumors with $\mathrm{T}_{3}$ and $\mathrm{T}_{4}$ staging have a poorer prognosis, and there is no data regarding the effects of surveillance on these locally advanced neoplasms. Therefore, such cases need an urgency for surgical intervention. Cytoreductive Nephrectomy has shown a survival benefit in appropriately selected patients with metastatic renal cell carcinoma (5). Two crucial randomized clinical trials (CARMENA and SURTIME) indicated that systemic therapy alone was 
non-inferior to cytoreductive nephrectomy followed by systemic therapy in the intermediate- and poor-risk group patients. It was also proven that deferred cytoreductive nephrectomy was not associated with poorer survival $(6,7)$. So, the treatment-decisions depending on patient factors should be made as per local tumor board or institutional policy on a priority basis.

Bladder Cancer, Upper Tract Urothelial Tumor (UTUC) There are some specific issues to be addressed in the context of the ongoing pandemic for the management of bladder and upper tract urothelial tumors. Patients presenting with macroscopic hematuria or clot retention warrant urgent cystoscopic intervention. Depending on the tumor burden and active bleeding, treatmentdecision of either a complete endoscopic tumor resection (TUR-BT) or controlling the bleeding vessels needs to be made. Obstructive complications arising from a bladder tumor infiltrating the ureteric orifice require emergency intervention.

For other bladder tumor patients who do not have active hematuria, the degree of urgency in surgical interventions depends upon specific clinical criteria. These encompass a single large tumor $(>3 \mathrm{~cm})$, multiple tumors, recurrent bladder tumor on follow-up, previous histology including high-grade tumor with positive urinary cytology, and presence or absence of carcinoma-in-situ (CIS).

\section{Intra-vesical Chemotherapy/Bacillus Calmette-Guérin Immunotherapy}

Intravesical instillation of chemotherapy (mitomycin C) in the immediate post-operative period (within 6 hours) has been shown to reduce the recurrence of bladder tumors (8). Given the low risk of systemic complications, it is widely practiced and can be safely administered to most patients.

Intravesical BCG immunotherapy is the only treatment shown to reduce or delay the progression of high-grade urothelial bladder cancer. It is given as a 6-week induction course, initiated 2 to 4 weeks after completion of TURBT. This is followed by a maintenance regimen along with regular cystoscopic surveillance. Bacillus CalmetteGuérin (BCG) is contraindicated in immunosuppressed or immunocompromised patients, active gross or microscopic hematuria, traumatic catheterization and, in patients with total incontinence. Urinary tract infection, liver disease (it disqualifies treatment with anti-tubercular medications in case of sepsis), and personal history of tuberculosis are relative contraindications (9). In the time of the pandemic, it is a must to test these patients for the presence of coronavirus infection before immunotherapy. Patients should be counselled about the warning signs of BCG immunotherapy adverse effects like fever and BCG sepsis. Non-steroidal anti-inflammatory drugs (NSAIDs) are commonly prescribed in cases of Grade 1
BCG toxicity as per the Cleveland Clinic Approach (9). It has been shown that COVID infected patients have worse outcomes due to NSAID, hence it is crucial to avoid these drugs during this pandemic (10). Other medications like topical antispasmodics (phenazopyridine) and anticholinergics are also efficacious in the management of Grade I toxicity. In the case of non-responders, a course of oral fluoroquinolone (ofloxacin, levofloxacin) is recommended.

\section{Radical Cystectomy}

Radical cystectomy (RC) with urinary diversion is the cornerstone in the management of muscle-invasive bladder cancer (MIBC) and patients with non-muscle invasive disease (NMIBC) are selected. Patients with NMIBC having $\mathrm{T}_{1}$ high-grade tumor with CIS, lymphovascular invasion, multifocal tumors, BCG unresponsive or failure and tumor size $>3 \mathrm{~cm}$ are also candidate for RC. The ideal duration between the diagnosis and $\mathrm{RC}$ for definitive management should be 10 to 12 weeks. It has been shown that delaying RC affects the outcome. Boeri et al reported that increased waiting period ( $>10$ weeks) to undergo RC was linked with adverse and cancer-specific survival (11). Considering the circumstances and if resources permit, eligible patients should undergo a timely intervention.

\section{Radical Nephroureterectomy}

Radical Nephroureterectomy with excision of bladder cuff is the treatment of choice for upper tract urothelial tumors (UTUCs). Similar to the outcomes in the bladder tumors, UTUC carries a risk of invasive disease, and a delay ( $>3$ months) in definitive management is associated with disease progression or upstaging and poor cancer-specific survival (12).

\section{Prostate Cancer}

Treatment of localized prostate cancer should be planned as per the risk stratification. The treatment of patients diagnosed with low- and intermediate-risk localized cancer can be postponed without any major impact on the outcomes. Low-risk cases should be assigned to active surveillance. For intermediate-risk cases, a delay of two months has shown no substantial impact on cancer outcomes. In high-risk cases and locally advanced cases, most laparoscopic or robotic-assisted radical prostatectomies should be delayed or given a low-priority. The Society of American Gastrointestinal and Endoscopic Surgeons (SAGES) (13) and the Royal College of Surgeons (RCS) (14) recommend deferring laparoscopic and robotic-assisted surgeries wherever possible and recommend open surgical procedures. The minimallyinvasive procedures risk potential contact with aerosols within the surgical smoke (15). Shared-decision making should be considered for employing radical radiotherapy for high-risk diseases. There is no clear cut-off time 
suggested in high-risk cases to safely defer treatment as the chances of biochemical recurrence rates increase in the absence of definitive treatment $(16,17)$. In patients who are ineligible for radiation therapy, surgery should be considered.

For metastatic prostate cancer, androgen deprivation therapy by using either GnRH agonists or antagonists followed by second-generation antiandrogens is preferable. Abiraterone acetate is the preferred drug in this setting; however, due to the need for corticosteroid supplementation, its use does not appear safe during this pandemic. Hence, the use of enzalutamide is desirable. Chemotherapy with docetaxel should also be avoided due to the risk of immunosuppression. A subset of patients may present with serious complications like spinal cord compression due to vertebral metastasis and obstructive uropathy due to locally advanced disease. These cases, without a doubt, require emergent intervention and hence should be managed accordingly.

\section{Cancers of the External Genitalia Penile Cancer}

Penile cancers are quite uncommon, which limits our understanding and presents a challenge in management. Penile cancers are already subject to delay in the diagnosis due to lack of awareness (18). A significant delay can decrease the likelihood of curative treatment. One study showed that 12 weeks was the ideal time for lymph nodal management to achieve a good oncological outcome (19). Organ preserving treatment, whenever feasible, should be prioritized. Partial or total penectomy offers a chance for a cure when performed timely. It should be offered at the earliest, bearing in mind it can be performed under regional anesthesia without much strain on resources. Nodal metastasis is the most crucial prognostic factor in penile cancer (20). Addressing the lymph nodes at the same time, even if clinically negative, can pick up to $25 \%$ cases of micro-metastasis. Pathological $\mathrm{N}_{0}$ disease has exceptional disease-specific survival rate approaching $80 \%$ at 5 -year follow up (21). Considering these factors,

Table 1. Suggested triage of urological cancers during the COVID-19 pandemic

\begin{tabular}{|c|c|c|c|c|}
\hline $\begin{array}{l}\text { Urological } \\
\text { cancers }\end{array}$ & $\begin{array}{l}\text { Low priority } \\
\text { (to be addressed within } 6 \\
\text { months) }\end{array}$ & $\begin{array}{l}\text { Intermediate priority } \\
\text { (to be addressed within } 3 \text { months) }\end{array}$ & $\begin{array}{l}\text { High priority } \\
\text { (to be addressed within } 6 \text { weeks) }\end{array}$ & $\begin{array}{l}\text { Emergency } \\
\text { (to be addressed within } 24 \\
\text { hours) }\end{array}$ \\
\hline Renal cancer & $\begin{array}{l}\text { - Partial nephrectomy } \\
\text { for small renal } \\
\text { masses }<4 \mathrm{~cm} \\
\text { Renal mass biopsy } \\
\text { for SRM }\end{array}$ & $\begin{array}{l}\text { Nephrectomy for cT1b-cT2a } \\
\text { tumors }\end{array}$ & $\begin{array}{ll}\text { - } & \text { Nephrectomy for cT3-T4 tumors } \\
\text { - } & \text { Renal tumor with IVC Thrombus } \\
\text { - } & \text { Retastatic renal cancer } \\
\text { - } & \text { Cytoreductive nephrectomy }\end{array}$ & $\begin{array}{l}\text { - Gross hematuria, } \\
\text { ureteric clot retention } \\
\text { Embolization of } \\
\text { actively bleeding } \\
\text { tumor }\end{array}$ \\
\hline $\begin{array}{l}\text { Bladder cancer } \\
\text { (NMIBC) }\end{array}$ & $\begin{array}{l}\text { TURBT and intravesical } \\
\text { therapy for low-grade } \\
\text { tumor }\end{array}$ & $\begin{array}{l}\text { TURBT and Intravesical therapy } \\
\text { for high-grade tumor }\end{array}$ & Radical cystectomy for multiple tumors & $\begin{array}{l}\text { Gross hematuria with clot } \\
\text { retention }\end{array}$ \\
\hline $\begin{array}{l}\text { Bladder cancer } \\
\text { (MIBC) }\end{array}$ & & $\begin{array}{l}\text { Neo-adjuvant chemotherapy for } \\
\text { T2 disease followed by radical } \\
\text { cystectomy }\end{array}$ & $\begin{array}{l}\text { - } \quad \text { Radical cystectomy based on disease } \\
\text { burden } \\
\text { MIBC- Neo-adjuvant chemotherapy } \\
\text { for T3/T4 disease } \\
\text { For metastatic MIBC - Consider } \\
\text { adding GCSF to chemotherapy }\end{array}$ & $\begin{array}{l}\text { - Gross hematuria with } \\
\text { clot retention } \\
\text { - Ureteric obstruction }\end{array}$ \\
\hline $\begin{array}{l}\text { Upper tract } \\
\text { urothelial } \\
\text { cancer }\end{array}$ & & $\begin{array}{l}\text { Diagnostic ureteroscopy and } \\
\text { Endourological treatment of small } \\
\text { tumor }\end{array}$ & $\begin{array}{l}\text { - Imaging for suspected upper tract } \\
\text { tumors } \\
\text { - } \quad \text { Radical nephroureterectomy }\end{array}$ & $\begin{array}{l}\text { Symptomatic patients, } \\
\text { hydronephrosis or } \\
\text { obstructed system }\end{array}$ \\
\hline Prostate cancer & $\begin{array}{l}\text { Active surveillance for } \\
\text { low-risk disease }\end{array}$ & $\begin{array}{l}\text { Radical prostatectomy for } \\
\text { intermediate risk disease }\end{array}$ & $\begin{array}{l}\text { Treat locally advanced disease with } \\
\text { immediate androgen deprivation } \\
\text { therapy (bilateral orchidectomy or } \\
\text { chemical castration). } \\
\text { - } \quad \text { mHSPC - consider enzalutamide } \\
\text { mCRPC chemotherapy for progressive } \\
\text { disease }\end{array}$ & $\begin{array}{l}\text { Metastatic prostate cancer: } \\
\text { ureteric obstruction, spinal } \\
\text { cord compression or } \\
\text { pathological fracture }\end{array}$ \\
\hline $\begin{array}{l}\text { Testicular } \\
\text { cancer }\end{array}$ & & & $\begin{array}{l}\text { - Imaging and orchidectomy at the } \\
\text { earliest. } \\
\text { Adjuvant therapy for Stage IIa/III } \\
\text { seminomatous GCT. } \\
\text { - } \quad \text { RPLND for residual mass. } \\
\text { Growing teratoma syndrome. }\end{array}$ & \\
\hline Penile cancer & & & $\begin{array}{l}\text { - } \quad \text { Partial or total penectomy } \\
\text { Inguinal node staging and appropriate } \\
\text { management }\end{array}$ & \\
\hline
\end{tabular}

SRM: Small renal mass; IVC: Inferior vena cava; NMIBC: Non-muscle invasive bladder cancer; MIBC: Muscle invasive bladder cancer; TURBT: Trans-urethral resection of bladder tumour; GCSF: Granulocyte colony stimulating factor; mHSPC: Metastatic hormone sensitive prostate cancer; mCRPC: Metastatic castrate resistant prostate cancer; GCT: Germ cell tumour; RPLND: Retro-peritoneal lymph node dissection. 
inguinal lymph node management should be given a priority.

\section{Testicular Tumors}

Testicular tumors should be dealt on a priority basis as there is a paucity of data on survival in these cases if a radical high-inguinal orchidectomy is delayed (22). Moreover, orchidectomy can be performed as an outpatient procedure under regional anesthesia without much burden on hospital resources. Post-orchidectomy management should depend upon the clinical and pathological staging and status of serum tumor markers. Surveillance is the most desirable option if a patient belongs to a good risk category. Chemotherapy, radiation therapy, and retroperitoneal lymph node dissection (RPLND) should be given due consideration when indicated as they have shown to improve survival. However, RPLND is associated with a significant burden on hospital resources since the average duration of hospital stay ranges from 4 to 6 days for open surgery. Other options must be explored. Laparoscopic or robotic approaches to RPLND are minimally-invasive; however, they should be deferred at this time. Chemotherapy use should also be balanced, taking into account the immunosuppression and increased risk of infection and poorer outcomes due to COVID-19.

\section{Conclusion}

The management of genitourinary malignancies should be timely done, especially the ones carrying poorer prognosis to provide the best outcomes. The judgment of delaying definitive treatment should depend upon presenting symptoms, disease characteristics, comorbid illnesses, access to health-care services, and availability of qualified health-care personnel (Table 1). We are facing a challenging task of taking such decisions considering that this pandemic has put the health-care system under unforeseen crisis. Evidence on these suggestions is limited; the directions might change over time as the pandemic evolves. It is difficult to predict the impact of this pandemic on the cancer patients; it surely depends on the duration of this global health emergency. We must provide support, a clear and comprehensible information along with essential care to the patients seeking medical opinion at this time. This should be tailored as per locally available health-care resources and the burden of COVID-19 infected cases in that region.

\section{Authors' contributions}

Study concept and design: MS, RBN. Data collection: MS, SCG. Analysis and Interpretation of data: MS, RBN. Draft Manuscript preparation: MS, SCG. All the authors reviewed the results and approved final version of the manuscript.

\section{Ethical issues}

Not applicable.
References

1. Nouhaud FX, Bernhard JC, Bigot P, Khene ZE, Audenet $\mathrm{F}$, Lang $\mathrm{H}$, et al. Contemporary assessment of the correlation between Bosniak classification and histological characteristics of surgically removed atypical renal cysts (UroCCR-12 study). World J Urol 2018; 36(10): 1643-9. doi: 10.1007/s00345-018-2307-6.

2. Mehrazin R, Smaldone MC, Kutikov A, Li T, Tomaszewski JJ, Canter DJ, et al. Growth kinetics and short-term outcomes of cT1b and cT2 renal masses under active surveillance. J Urol 2014; 192(3): 659-64. doi: 10.1016/j.juro.2014.03.038.

3. McIntosh AG, Ristau BT, Ruth K, Jennings R, Ross E, Smaldone MC, et al. Active surveillance for localized renal masses: tumor growth, delayed intervention rates, and > 5-yr clinical outcomes. Eur Urol 2018; 74(2): 157-64. doi: 10.1016/j.eururo.2018.03.011.

4. Pierorazio PM, Johnson MH, Ball MW, Gorin MA, Trock BJ, Chang P, et al. Five-year analysis of a multi-institutional prospective clinical trial of delayed intervention and surveillance for small renal masses: the DISSRM registry. Eur Urol 2015; 68(3): 408-15. doi: 10.1016/j. eururo.2015.02.001.

5. Nerli RB. Cytoreductive nephrectomy for metastatic renal cell carcinoma. J Sci Soc. 2013; 40(2): 64-7. doi: 10.4103/ kleuhsj.kleuhsj_116_20.

6. Méjean A, Ravaud A, Thezenas S, Colas S, Beauval JB, Bensalah K, et al. Sunitinib alone or after nephrectomy in metastatic renal-cell carcinoma. N Engl J Med 2018; 379(5): 417-27. doi: 10.1056/NEJMoa1803675.

7. Bex A, Mulders P, Jewett M, Wagstaff J, van Thienen JV, Blank CU, et al. Comparison of immediate vs deferred cytoreductive nephrectomy in patients with synchronous metastatic renal cell carcinoma receiving sunitinib: the SURTIME randomized clinical trial. JAMA Oncol 2019; 5(2): 164-70. doi: 10.1001/jamaoncol.2018.5543.

8. Barghi MR, Rahmani MR, Hosseini Moghaddam SM, Jahanbin M. Immediate intravesical instillation of mitomycin $\mathrm{C}$ after transurethral resection of bladder tumor in patients with low-risk superficial transitional cell carcinoma of bladder. Urol J 2006; 3(4): 220-4.

9. Jones JS. Non-muscle-invasive bladder cancer (Ta, T1, and CIS). In: Wein AJ, Kavoussi LR, Partin AW, Peters CA, eds. Campbell-Walsh Urology. 11th ed. Philadelphia: Elsevier; 2016. p. 2214-15.

10. Little P. Non-steroidal anti-inflammatory drugs and COVID-19. BMJ 2020; 368: m1185. doi: 10.1136/bmj. m1185.

11. Boeri L, Soligo M, Frank I, Boorjian SA, Thompson RH, Tollefson $\mathrm{M}$, et al. Delaying radical cystectomy after neoadjuvant chemotherapy for muscle-invasive bladder cancer is associated with adverse survival outcomes. Eur Urol Oncol 2019; 2(4): 390-6. doi: 10.1016/j. euo.2018.09.004.

12. Waldert M, Karakiewicz PI, Raman JD, Remzi M, Isbarn $\mathrm{H}$, Lotan $\mathrm{Y}$, et al. A delay in radical nephroureterectomy can lead to upstaging. BJU Int 2010; 105(6): 812-7. doi: 10.1111/j.1464-410X.2009.08821.x.

13. Pryor A. SAGES Recommendations Regarding Surgical Response to COVID-19 Crisis - SAGES [Internet]. Society of American Gastrointestinal and Endoscopic Surgeons. 
2020 [cited 24 Apr 2020]. Available from: https://www. sages.org/recommendationssurgical-response-covid-19/.

14. Updated Intercollegiate General Surgery Guidance on COVID-19 [Internet]. Royal College of Surgeons. 2020 [cited 24 Apr 2020]. Available from: https://www.rcseng. ac.uk/coronavirus/joint-guidance-for-surgeons-v2/.

15. Spinelli A, Pellino G. COVID-19 pandemic: perspectives on an unfolding crisis. Br J Surg 2020; 107(7): 785-7. doi: 10.1002/bjs.11627.

16. Fossati N, Rossi MS, Cucchiara V, Gandaglia G, Dell'Oglio P, Moschini M, et al. Evaluating the effect of time from prostate cancer diagnosis to radical prostatectomy on cancer control: can surgery be postponed safely? Urol Oncol 2017; 35(4): 150.e9-150.e15. doi: 10.1016/j.urolonc.2016.11.010.

17. Loeb S, Folkvaljon Y, Robinson D, Makarov DV, Bratt O, Garmo $\mathrm{H}$, et al. Immediate versus delayed prostatectomy: nationwide population-based study. Scand J Urol 2016; 50(4): 246-54. doi: 10.3109/21681805.2016.1166153.

18. Shabbir M, Kayes O, Minhas S. Challenges and controversies in the management of penile cancer. Nat Rev Urol 2014; 11(12): 702-11. doi: 10.1038/nrurol.2014.307.

19. Chipollini J, Tang DH, Gilbert SM, Poch MA, Pow-Sang JM, Sexton WJ, et al. Delay to inguinal lymph node dissection greater than 3 months predicts poorer recurrence-free survival for patients with penile cancer. J Urol 2017; 198(6): 1346-52. doi: 10.1016/j.juro.2017.06.076.

20. Ficarra V, Akduman B, Bouchot O, Palou J, Tobias-Machado M. Prognostic factors in penile cancer. Urology 2010; 76(2 Suppl 1): S66-73. doi: 10.1016/j.urology.2010.04.008.

21. Leone A, Diorio GJ, Pettaway C, Master V, Spiess PE. Contemporary management of patients with penile cancer and lymph node metastasis. Nat Rev Urol 2017; 14(6): 33547. doi: 10.1038/nrurol.2017.47.

22. Bourgade V, Drouin SJ, Yates DR, Parra J, Bitker MO, Cussenot $\mathrm{O}$, et al. Impact of the length of time between diagnosis and surgical removal of urologic neoplasms on survival. World J Urol 2014; 32(2): 475-9. doi: 10.1007/ s00345-013-1045-z. 